\title{
Protective effects of scopolamine and penehyclidine hydrochloride on acute cerebral ischemia-reperfusion injury after cardiopulmonary resuscitation and effects on cytokines
}

\author{
DENGQIN WANG $^{1 *}$, QI JIANG ${ }^{2 *}$ and XIULING DU ${ }^{3}$ \\ ${ }^{1}$ Clinical Medicine Skill Center, Jining Medical University, Jining, Shandong 272067; ${ }^{2}$ Department of Anesthesiology, \\ Xiangyang No. 1 People's Hospital Affiliated to Hubei University of Medicine, Xiangyang, Hubei 441000; \\ ${ }^{3}$ Endoscopy Center, Binzhou City Center Hospital, Binzhou, Shandong 251700, P.R. China
}

Received July 7, 2017; Accepted November 21, 2017

DOI: $10.3892 / \mathrm{etm} .2017 .5646$

\begin{abstract}
The objective of this study was to investigate the protective effects of scopolamine and penehyclidine hydrochloride on acute cerebral ischemia-reperfusion injury after cardiopulmonary resuscitation, and the effect on cytokine levels. Eighty patients with cardiac arrest admitted to our hospital from June 2011 to December 2015 were recruited and randomly divided into two groups $(\mathrm{n}=40 \mathrm{each})$. Following cardiopulmonary resuscitation, scopolamine was administered in the control group, whereas penehyclidine hydrochloride was administered in the observation group. After intervention, the following medical indicators were compared between the groups: Intracranial pressure, cerebral oxygen partial pressure, cerebral perfusion pressure, assessment of the balance of cerebral oxygen supply and demand, levels of neuron-specific enolase (NSE) and blood lactic acid, levels of oxidative stress markers, and levels of inflammatory-related factors. Additionally, the areas of brain tissue edema and National Institutes of Health Stroke Scale (NIHSS) scores before and after intervention were compared. Rescue success rates of the groups were recorded. After intervention, the following indicators were lower in the observation group than in the control group: Intracranial pressure $(p<0.05)$, levels of NSE $(p<0.05)$, levels of blood lactic acid ( $<<0.05)$, levels of malondialdehyde $(\mathrm{p}<0.05)$, and levels of interleukin 6 (IL-6), tumor necrosis factor- $\alpha$, IL-1, and hs-CRP $(p<0.05)$. However, the following indicators were higher in the observation group than in the
\end{abstract}

Correspondence to: Dr Dengqin Wang, Clinical Medicine Skill Center, Jining Medical University, 16 Hehua Road, Beihu, Jining, Shandong 272067, P.R. China

E-mail: dengqinwang17@163.com

"Contributed equally

Key words: penehyclidine, cardiopulmonary resuscitation, cerebral ischemia-reperfusion injury, cerebral protection, cytokines, scopolamine control group: Cerebral oxygen partial pressure, cerebral perfusion pressure $(\mathrm{p}<0.05)$, levels of $\mathrm{CaO}_{2}, \mathrm{CjvO}_{2}$, and $\mathrm{CERO}_{2}$ ( $p>0.05)$, and levels of superoxide dismutase and glutathione peroxidase $(\mathrm{p}<0.05)$. Additionally, the areas of brain tissue edema after intervention were smaller in the observation group than those before intervention and those after intervention in the control group $(\mathrm{p}<0.05)$. Similarly, the NIHSS scores after intervention in the observation group were lower than those before intervention and those after intervention in the control group $(\mathrm{p}<0.05)$. Rescue success rate was significantly higher in observation group than in control group $(\mathrm{p}<0.05)$. In conclusion, administration of penehyclidine following cardiopulmonary resuscitation can effectively improve cerebral perfusion pressure, lower intracranial pressure, reduce brain tissue edema and inflammation, and improve neurological function.

\section{Introduction}

Cardiopulmonary resuscitation refers primarily to a procedure involving repeated chest compressions and artificial respiration in an attempt to maintain the circulation of a patient suffering from respiratory or cardiac arrest resulting from any cause (1). Respiratory and cardiac arrest are among the most critical clinical conditions, for which treatment is a race against time (2). This is especially true for older patients with significantly declined body functions that result in high sensitivity and poor tolerance to hypoxia. It was confirmed that $(3,4)$ both spontaneous respiration and the heartbeat can be restored in some older patients with cardiac and respiratory arrest, if it is detected early, and treated immediately and appropriately. Early detection and immediate and appropriate treatment can reduce the impact of respiratory and cardiac arrest on the functions of key organs, and is therefore the key to a successful rescue. The recovery rate of cerebral resuscitation in the basic stage of cardiopulmonary resuscitation is relatively low, while the efficiency of cerebral resuscitation is closely related to the prognosis and quality of life of patients (5). Therefore, procedures that can effectively improve the efficiency of cardiopulmonary resuscitation, especially the result of cerebral resuscitation, are of 
great significance in increasing the success rate of rescue, and improving the prognosis of patients (6). Scopolamine is a medication used in the treatment of cardiac arrest. Its clinical value for improving spontaneous circulation and the success rate of resuscitation have been recognized. However, long-term use of scopolamine can lead to decreased secretion, dysuria, and excessive vascular dilatation. Importantly, it has a negative effect on cerebral resuscitation in patients on advanced life support (7). Penehyclidine is currently the most commonly used anticholinergic drug, and is primarily administered for rescue from organophosphorus pesticide poisoning. Its application in cardiopulmonary resuscitation is less well understood. In this study, the two drugs were assessed and compared for their effects in cardiopulmonary resuscitation.

\section{Patients and methods}

Patients. Eighty patients with cardiac arrest admitted to Clinical Medicine Skill Center from June 2011 to December 2015 were recruited in this study. All patients were diagnosed with sudden cardiac arrest resulting from acute myocardial infarction. Patients were diagnosed according to clinical symptoms and ECG. Patients with other conditions such as severe liver and kidney dysfunction, chronic respiratory diseases, neurological diseases, previous cardiopulmonary surgery, mental illness, coagulation disorders, and congenital heart disease were excluded. A consent form was signed by the patient's families before recruitment, and the study was approved by the Ethics Committee of Jining Medical University (Shandong, China). The patients were randomly and equally divided into two groups, with 40/group. Among the two groups, the observation group included 23 males and 17 females, aged 50-70 years, with an average age of 62.3 \pm 2.1 years, who underwent cardiopulmonary cerebral resuscitation from $15 \mathrm{sec}$ to $15 \mathrm{~min}$, with and average of $3.1 \pm 0.2 \mathrm{~min}$ post-cardiac arrest. The control group included 24 males and 16 females, aged 50-70 years, with an average age of $62.4 \pm 2.0$ years, who underwent cardiopanulmonary cerebral resuscitation from $15 \mathrm{sec}$ to $15 \mathrm{~min}$, with an average time of $3.0 \pm 0.2 \mathrm{~min}$ post-cardiac arrest. There were no significant differences in sex, age, or the time from cardiac arrest to implementation of cardiopulmonary cerebral resuscitation between the two groups ( $\mathrm{p}>0.05)$.

Methods. Cardiopulmonary resuscitation was performed on all participants in accordance with the 2010 American Heart Association Guidelines for Cardiopulmonary Resuscitation. Tracheal intubation was performed promptly by anesthetists, and ventilation was achieved either through artificial ventilation or ventilator-assisted ventilation. Different drugs were chosen and administered depending on the efficiency of cardiopulmonary resuscitation, including atropine, adrenaline, sodium bicarbonate, calcium gluconate, norepinephrine, and other vasoactive agents. When spontaneous heartbeat was restored, patients in the control group were administered scopolamine (CFDA approval no. H33021707 granted to Hangzhou Minsheng Pharmaceutical Co., Ltd., Hangzhou, China). First, a $40 \mathrm{mg}$ bolus of the drug was administered via intravenous injection, followed by an additional $80 \mathrm{mg}$ administered by an intravenous infusion pump for $24 \mathrm{~h}$. Patients in the observation group were administered penehyclidine hydrochloride (CFDA approval no. 0060H2620 granted to Chengdu List Pharmaceutical Co., Ltd., Chengdu, China). First, a 2 mg bolus of the drug was administered via intravenous injection, followed by an additional $4 \mathrm{mg}$ administered by an infusion pump for $24 \mathrm{~h}$.

Medical indicators. After intervention, the following medical indicators were compared between the two groups: Intracranial pressure, cerebral oxygen partial pressure, cerebral perfusion pressure (CPP), assessment of the balance of cerebral oxygen supply and demand, levels of neuron-specific enolase (NSE) and blood lactic acid, levels of oxidative stress markers, and levels of inflammatory-related factors. In addition, the areas of brain tissue edema and the National Institutes of Health Stroke Scale (NIHSS) scores before and after intervention were compared. Rescue success rates of two groups were recorded.

Criteria of indicators. For measurement of intracranial indicators, lumbar puncture and lumbar cistern intubation were performed on patients to measure intracranial pressure, and cerebral oxygen partial pressure was measured by a cerebral oxygen partial pressure probe. Simultaneously, a pressure sensor was connected. The CPP was the difference between mean arterial blood pressure and intracranial pressure. Blood gas analysis was performed on radial artery and jugular venous blood collected from the patients. With a specific formula, the data were used to calculate arterial oxygen content $\left(\mathrm{CaO}_{2}\right)$, venous oxygen content $(\mathrm{CjvO})$, the difference between arterial and venous oxygen content $\left(\mathrm{Da}-\mathrm{jvO}_{2}\right)$, and cerebral oxygen uptake rate $\left(\mathrm{CERO}_{2}\right)$. The levels of NSE were measured by enzyme-linked immunosorbent assay (ELISA; reference values below $12.5 \mathrm{U} / \mathrm{ml}$ ). The levels of lactic acid were determined by neutralization titration [reference values from 0.5-1.7 mmol/1 (5-15 mg/dl)]. The immunoassay kit and lactic acid assay kit were from Shanghai Huamei Biology Co., Ltd. (Shanghai, China). The levels of malondialdehyde (MDA), superoxide dismutase (SOD), and glutathione peroxidase (GSH-Px) in blood were measured by spectrophotometry, enzyme rate assay, and colorimetric assay, respectively. The adult reference values for MAD, SOD, and GSH-Px were 3.52-4.78 nmol/ml, 242-620 U/1, and 26-34 U/1, respectively. The levels of all inflammation-related factors were determined by ELISA, including tumor necrosis factor- $\alpha$ (TNF- $\alpha$ ) (adult reference values, 1-10 ng/ml), IL-1 (adult reference values, 130-250 ng/ml), IL-6 (adult reference values, 67.37-150.33 ng/l), and hs-CRP (adult reference values, $<10 \mathrm{mg} / \mathrm{l}$ ). Neurological function was assessed using NIHSS scores, with a maximum score of 42 points among 11 items. The area of brain tissue edema before and after intervention was measured using head magnetic resonance imaging (MRI) by two radiologists in conjunction who each had over 5 years of experience in operating and interpreting MRI.

Statistical analysis. SPSS 13.0 statistical software (IBM Corp., Armonk, NY, USA) was used for data analysis. Numerical 
Table I. Intracranial pressure, cerebral oxygen partial pressure and CPP after intervention.

\begin{tabular}{lccc}
\hline & $\begin{array}{c}\text { Intracranial } \\
\text { pressure } \\
(\mathrm{mmHg})\end{array}$ & $\begin{array}{c}\text { Cerebral oxygen } \\
\text { partial pressure } \\
(\mathrm{mmHg})\end{array}$ & $\begin{array}{c}\mathrm{CPP} \\
(\mathrm{mmHg})\end{array}$ \\
\hline Obroups & $17.6 \pm 3.2$ & $23.1 \pm 2.4$ & $66.1 \pm 10.9$ \\
Control $(\mathrm{n}=40)$ & $20.3 \pm 4.1$ & $21.6 \pm 2.1$ & $61.3 \pm 9.3$ \\
t-test & 3.283 & 2.975 & 2.119 \\
P-value & 0.002 & 0.004 & 0.037 \\
\hline
\end{tabular}

$\mathrm{CPP}$, cerebral perfusion pressure.

Table II. Supply and demand of brain oxygen after intervention.

\begin{tabular}{lccc}
\hline Group & $\mathrm{CaO}_{2}(\mathrm{ml} / \mathrm{l})$ & $\mathrm{CjvO}_{2}(\mathrm{ml} / \mathrm{l})$ & $\mathrm{CERO}_{2}(\mathrm{ml} / \mathrm{l})$ \\
\hline Observation $(\mathrm{n}=40)$ & $165.1 \pm 23.1$ & $113.5 \pm 16.1$ & $35.6 \pm 5.6$ \\
Control $(\mathrm{n}=40)$ & $152.3 \pm 21.3$ & $105.9 \pm 14.6$ & $31.1 \pm 4.0$ \\
t-test & 2.576 & 2.212 & 4.136 \\
P-value & 0.012 & 0.030 & $<0.001$ \\
\hline
\end{tabular}

$\mathrm{CaO}_{2}$, arterial oxygen content; $\mathrm{CjvO}_{2}$, venous oxygen content; $\mathrm{CERO}_{2}$, cerebral oxygen uptake rate.

Table III. Levels of NSE and blood lactic acid after intervention.

\begin{tabular}{lcc}
\hline Group & NSE (U/ml) & $\begin{array}{c}\text { Blood lactic acid } \\
(\mathrm{mmol} / \mathrm{l})\end{array}$ \\
\hline Observation $(\mathrm{n}=40)$ & $16.1 \pm 0.2$ & $1.2 \pm 0.1$ \\
Control $(\mathrm{n}=40)$ & $25.5 \pm 1.1$ & $1.9 \pm 0.3$ \\
t-test & 53.174 & 14.000 \\
P-value & $<0.001$ & $<0.001$ \\
\hline
\end{tabular}

NSE, neuron-specific enolase.

data are presented as mean \pm standard deviation. The t-test was used for comparisons of mean values between the two groups. The $\chi^{2}$ test was used for comparisons of ratios between the two groups. $\mathrm{P}<0.05$ was considered to indicate a statistically significant difference.

\section{Results}

Intracranial pressure, cerebral oxygen partial pressure, and CPP after intervention. After intervention, intracranial pressure was lower $(\mathrm{p}<0.05)$, while cerebral oxygen partial pressure and CPP were higher $(\mathrm{p}<0.05)$ in the observation group than in the control group (Table I).

Supply and demand of brain oxygen after intervention. After intervention, the levels of $\mathrm{CaO}_{2}, \mathrm{CjvO}_{2}$, and $\mathrm{CERO}_{2}$ were higher in the observation group than in the control group (p>0.05) (Table II).
Table IV. Levels of oxidative stress markers after intervention.

\begin{tabular}{lccc}
\hline Group & $\begin{array}{c}\text { MDA } \\
(\mathrm{nmol} / \mathrm{ml})\end{array}$ & SOD (U/1) & GSH-Px (U/l) \\
\hline Observation (n=40) & $3.6 \pm 0.2$ & $378.5 \pm 26.6$ & $38.0 \pm 4.2$ \\
Control (n=40) & $7.1 \pm 1.0$ & $195.0 \pm 11.4$ & $21.2 \pm 3.1$ \\
t-test & 21.706 & 40.102 & 20.354 \\
P-value & $<0.001$ & $<0.001$ & $<0.001$ \\
\hline
\end{tabular}

MDA, malondialdehyde; SOD, superoxide dismutase; GSH-Px, glutathione peroxidase.

Table V. Levels of inflammation-related factors after intervention.

\begin{tabular}{lcccc}
\hline Group & $\begin{array}{c}\text { IL-6 } \\
(\mathrm{ng} / \mathrm{l})\end{array}$ & $\begin{array}{c}\text { TNF- } \alpha \\
(\mathrm{ng} / \mathrm{ml})\end{array}$ & $\begin{array}{c}\text { IL-1 } \\
(\mathrm{ng} / \mathrm{l})\end{array}$ & $\begin{array}{c}\text { hs-CRP } \\
(\mathrm{mg} / \mathrm{l})\end{array}$ \\
\hline Observation $(\mathrm{n}=40)$ & $34.6 \pm 6.1$ & $12.1 \pm 0.2$ & $0.61 \pm 0.1$ & $10.5 \pm 1.0$ \\
Control (n=40) & $153.2 \pm 14.1$ & $18.3 \pm 0.5$ & $0.93 \pm 0.2$ & $31.1 \pm 2.0$ \\
t-test & 48.825 & 72.815 & 9.051 & 58.266 \\
P-value & $<0.001$ & $<0.001$ & $<0.001$ & $<0.001$
\end{tabular}

IL, interleukin; TNF- $\alpha$, tumor necrosis factor- $\alpha$.

Levels of NSE and blood lactic acid after intervention. After intervention, the levels of NSE and blood lactic acid were lower in the observation group than in the control group $(\mathrm{p}<0.05)$ (Table III).

Levels of oxidative stress markers after intervention. After intervention, the levels of SOD and GSH-Px were higher $(p<0.05)$, while the levels of MDA were lower $(p<0.05)$ in the observation group than in the control group (Table IV).

Levels of inflammation-related factors after intervention. After intervention, the levels of IL-6, TNF- $\alpha$, IL-1, and hs-CRP were lower in the observation group than in the control group $(\mathrm{p}<0.05)$ (Table V).

Area of brain tissue edema before and after intervention. There was no significant difference in the area of brain tissue edema between the two groups before intervention $(p>0.05)$. The areas of brain tissue edema in the observation group were smaller than those before intervention, and those of the control group after intervention $(\mathrm{p}<0.05)$ (Table VI).

NIHSS score before and after intervention. There were no significant differences in NIHSS scores between the two groups before intervention ( $p>0.05)$. The NIHSS scores after intervention in the observation group were lower than those before intervention, and those in the control group after intervention $(\mathrm{p}<0.05)$ (Table VII).

Comparison of successful rescue rate between two groups. There were 38 cases of successful rescue in observation group 
Table VI. Area of brain tissue edema before and after intervention.

\begin{tabular}{lcccc}
\hline & $\begin{array}{c}\text { Area before } \\
\text { intervention } \\
\left(\mathrm{cm}^{2}\right)\end{array}$ & $\begin{array}{c}\text { Area after } \\
\text { intervention } \\
\left(\mathrm{cm}^{2}\right)\end{array}$ & t-test & P-value \\
\hline Observation $(\mathrm{n}=40)$ & $4.0 \pm 0.3$ & $2.0 \pm 0.1$ & 40.000 & $<0.01$ \\
Control $(\mathrm{n}=40)$ & $4.1 \pm 0.3$ & $3.5 \pm 0.3$ & 8.944 & $<0.01$ \\
t-test & 0.981 & 30.000 & - & - \\
P-value & 0.121 & $<0.01$ & - & - \\
\hline
\end{tabular}

Table VII. NIHSS score before and after intervention.

\begin{tabular}{lcccc}
\hline & $\begin{array}{c}\text { Before } \\
\text { intervention } \\
\text { (points) }\end{array}$ & $\begin{array}{c}\text { After } \\
\text { intervention } \\
\text { (points) }\end{array}$ & t-test & P-value \\
\hline Observation (n=40) & $23.5 \pm 3.3$ & $10.3 \pm 1.1$ & 24.000 & $<0.01$ \\
Control (n=40) & $23.5 \pm 3.4$ & $19.5 \pm 2.4$ & 6.079 & $<0.01$ \\
t-test & $<0.01$ & 22.039 & - & - \\
P-value & 1.000 & $<0.01$ & - & - \\
\hline
\end{tabular}

NIHSS, National Institutes of Health Stroke Scale.

(95.0\%) and 28 cases in control group (70.0\%). Success rate of rescue in observation group was significantly higher than in control group $\left(\chi^{2}=7.013 ; \mathrm{p}=0.008\right)$.

\section{Discussion}

With the widespread procedures for cardiopulmonary resuscitation and the knowledge of public medical emergencies, some patients with cardiac arrest can be effectively rescued before hospital admission (8). Patients who suffer from cardiac arrest can also be rescued with a high success rate (9). The recovery rate of cerebral resuscitation in the basic stage of cardiopulmonary resuscitation is relatively low, while the efficiency of cerebral resuscitation is closely related to prognosis and the quality of life of patients. Presently, the most effective procedures to rescue patients with cardiac arrest include chest compression, tracheal intubation to assist breathing, head cooling, and other supporting treatments for cardiopulmonary cerebral resuscitation (10). When the aforementioned cardiopulmonary resuscitation procedures are performed on patients with sudden respiratory and cardiac arrest, drugs should also be administered to increase the success rate of rescue, improve the outcome of cerebral resuscitation, and further improve patient prognosis (11-13).

In this study, the effects of scopolamine and penehyclidine hydrochloride on the prevention and treatment of acute cerebral ischemia-reperfusion injury after cardiopulmonary resuscitation were investigated. It was found that after drug intervention, intracranial pressures were lower, while other indicators including the cerebral oxygen partial pressures and CPP, and the levels of $\mathrm{CaO}_{2}, \mathrm{CjvO}_{2}$, and $\mathrm{CERO}_{2}$ were higher in the observation group than in the control group.
These results demonstrated that administration of penehyclidine hydrochloride after undergoing cardiopulmonary resuscitation can significantly improve cerebral oxygen partial pressure, increase CPP, reduce intracranial pressure, substantially improve cerebral oxygen supply, and reduce oxygen consumption. Administration of penehyclidine can significantly delay calcium ion outflow in neuronal cytoplasm, thereby blocking L-type calcium channel expansion. This in turn results in inhibition of calcium ion transport across the cell membrane, and calcium ion release from the endoplasmic reticulum. Eventually, ATP activity is lost in neurons (13), and the occurrence of calcium overload is reduced, thereby reducing cerebral ischemia-reperfusion injury and the formation of oxygen free radicals. Administration of penehyclidine can also reduce endothelial cell damage caused by neutrophil infiltration (14). It was demonstrated that when cerebrovascular expansion occurs, oxygen supply and CPP are increased significantly (15), while the average arterial pressure does not change significantly. Therefore, intracranial pressure is relatively reduced. Comparing the levels of NSE and blood lactic acid after intervention, it was found that both the levels of NSE and blood lactic acid were lower in the observation group than in the control group. These results suggested that administration of penehyclidine after undergoing cardiopulmonary resuscitation can effectively reduce the levels of NSE and lactic acid. The underlying mechanism likely is that penehyclidine can effectively improve cell tolerance to ischemia and hypoxia, maintain lysosomal and mitochondrial activity, and reduce the levels of arachidonic acid in the body (16). Penehyclidine was shown to further reduce capillary permeability, and play a role in vasodilation and improvement of local microcirculation (17). In addition, penehyclidine has a certain degree of anti-lipid peroxidation activity (18). Therefore, administration of penehyclidine can significantly reduce the levels of NSE and lactic acid. In the analysis of oxidative stress response and inflammatory cytokines, it was found that the levels of oxidative stress markers, SOD and GSH-Px, were higher, while the levels of MDA were lower in the observation group than in the control group. Additionally, the levels of all observed inflammatory cytokines (IL-6, TNF- $\alpha$, IL-1, and hs-CRP) were lower in the observation group than in the control group after intervention. These results indicated that administration of penehyclidine to patients undergoing cardiopulmonary resuscitation can significantly reduce the body's inflammatory response and oxidative stress response. Cerebral ischemia and reperfusion injury during cardiopulmonary resuscitation is related to the inflammatory responses of neuronal cells, glial cells, and vascular endothelial cells at the site of injury (18). The above biochemical markers are all associated with $\mathrm{NF}-\kappa \mathrm{B}$ gene expression. Therefore, effective modulation of $\mathrm{NF}-\kappa \mathrm{B}$ activity plays a key role in the treatment of cerebral resuscitation (19). Penehyclidine can effectively penetrate the blood-brain barrier, and reach effective drug concentrations in the brain. By selectively binding receptors of the M1 and M3 subtypes and N1 and N2 subtypes, it has anticholinergic effects in the central nervous system, and effectively inhibits $\mathrm{NF}-\kappa \mathrm{B}$ protein activity (20). Comparing the areas of brain tissue edema and NIHSS scores before and after intervention, it was found that the areas of brain tissue edema were smaller and the NIHSS scores were lower in the observation group 
after intervention than those before intervention, and those in the control group after intervention. These results suggested that administration of penehyclidine to patients undergoing cardiopulmonary resuscitation is of great value in reducing brain edema and improving the patient's neurological function. The mechanism is probably related to the good blood-brain barrier permeability of the drug, and its selective binding to acetylcholine receptors, thus reducing cerebral vascular endothelial permeability as well as cerebral edema, and improving neurological function (20).

In conclusion, administration of penehyclidine to patients undergoing cardiopulmonary resuscitation can effectively improve CPP, lower intracranial pressure, reduce cerebral edema and inflammation, and eventually improve neurological function.

\section{References}

1. Shu Y, Li Z and Han B: Penehyclidine hydrochloride postconditioning ameliorates cerebral ischemia-reperfusion injury: Critical role of mitochondrial ATP sensitive potassium channel. J Biol Regul Homeost Agents 30: 41-53, 2016.

2. Kim KY, Cho HS, Lee SH, Ahn JH and Cheon HG: Neuroprotective effects of KR-62980, a new PPAR $\gamma$ agonist, against chemical ischemia-reperfusion in SK-N-SH cells. Brain Res 1372: 103-114, 2011.

3. Yan HD, Wang Z and Qian JQ: Efficient kinetic resolution of (RS)-1-phenylethanol by a mycelium-bound lipase from a wild-type Aspergillus oryzae strain. Biotechnol Appl Biochem 64: 251-258, 2017.

4. Shu Y, Yang Y and Zhang P: Neuroprotective effects of penehyclidine hydrochloride against cerebral ischemia/reperfusion injury in mice. Brain Res Bull 121: 115-123, 2016.

5. Wang Y, Ma T, Zhou L, Li M, Sun XJ, Wang YG and Gu S: Penehyclidine hydrochloride protects against oxygen and glucose deprivation injury by modulating amino acid neurotransmitters release. Neurol Res 35: 1022-1028, 2013.

6. Cao HJ, Sun YJ, Zhang TZ, Zhou J and Diao YG: Penehyclidine hydrochloride attenuates the cerebral injury in a rat model of cardiopulmonary bypass. Can J Physiol Pharmacol 91: 521-527, 2013.

7. Ma TF, Zhou L, Wang Y, Qin SJ, Zhang Y, Hu B, Yan JZ, Ma X, Zhou CH and Gu SL: A selective M1 and M3 receptor antagonist, penehyclidine hydrochloride, prevents postischemic LTP: Involvement of NMDA receptors. Synapse 67: 865-874, 2013.

8. Yu C and Wang J: Neuroprotective effect of penehyclidine hydrochloride on focal cerebral ischemia-reperfusion injury. Neural Regen Res 8: 622-632, 2013.

9. Wang Y, Ma T, Li M, Sun X, Wang Y and Gu S: Regulated hypoxia/reperfusion-dependent modulation of ERK1/2, cPLA2, and Bcl-2/Bax: A potential mechanism of neuroprotective effect of penehyclidine hydrochloride. Int J Neurosci 121: 442-449, 2011.
10. Wang YA, Zhou WX, Li JX, Liu YQ, Yue YJ, Zheng JQ, Liu KL and Ruan JX: Anticonvulsant effects of phencynonate hydrochloride and other anticholinergic drugs in soman poisoning: Neurochemical mechanisms. Life Sci 78: 210-223, 2005.

11. Huang C, He J, Chen Y, Zhang Y and Chen C: Penehyclidine hydrochloride inhibits the LPS-induced inflammatory response in microglia. J Surg Res 188: 260-267, 2014.

12. Yang Q, Liu X, Yao Z, Mao S, Wei Q and Chang Y: Penehyclidine hydrochloride inhibits the release of high-mobility group box 1 in lipopolysaccharide-activated RAW264.7 cells and cecal ligation and puncture-induced septic mice. J Surg Res 186: 310-317, 2014.

13. Mu DL, Li LH, Wang DX, Li N, Shan GJ, Li J, Yu QJ and Shi CX: High postoperative serum cortisol level is associated with increased risk of cognitive dysfunction early after coronary artery bypass graft surgery: A prospective cohort study. PLoS One 8: e77637, 2013

14. Cui J, Li CS, He XH and Song YG: Protective effects of penehyclidine hydrochloride on acute lung injury caused by severe dichlorvos poisoning in swine. Chin Med J (Engl) 126: 4764-4770, 2013.

15. Xia B, Li J, Yang D, Mei W, Ding L and Zhou Y: A rapid and highly specific method to evaluate the presence of 2-(2-phenylethyl) chromones in agarwood by supercritical fluid chromatography-mass spectrometry. Eur J Mass Spectrom Chichester 20: 395-402, 2014.

16. Fadhel AZ, Pollet P, Liotta CL and Eckert CA: Combining the benefits of homogeneous and heterogeneous catalysis with tunable solvents and nearcritical water. Molecules 15: 8400-8424, 2010.

17. Pereira-Caro G, Mateos R, Saha S, Madrona A, Espartero JL, Bravo L and Kroon PA: Transepithelial transport and metabolism of new lipophilic ether derivatives of hydroxytyrosol by enterocyte-like Caco-2/TC7 cells. J Agric Food Chem 58: $11501-11509,2010$

18. Sun YJ, Song DD, Diao YG, Zhou J and Zhang TZ: Penehyclidine hydrochloride preserves the intestinal barrier function in patients undergoing cardiopulmonary bypass. J Thorac Cardiovasc Surg 146: 179-185, 2013.

19. Pandit JJ, Picton P and Mashour GA: Penehcyclidine and awareness during anaesthesia: Caution with zero numerators. Anaesthesia 68: 131-135, 2013.

20. Zhang Z, Zhuang Y, Ouyang F, Zhang A, Zeng B and Gu M: Penehyclidine enhances the efficacy of tropisetron in prevention of PONV following gynecological laparoscopic surgery. J Anesth 26: 864-869, 2012.

This work is licensed under a Creative Commons Attribution-NonCommercial-NoDerivatives 4.0 International (CC BY-NC-ND 4.0) License. 